\title{
Fatal case of COVID-19 in a 27-year-old woman with diabetes mellitus
}

\author{
Christine Schlömmer · Martin W. Dünser · Marlies Antlanger · Christian Paar · Markus Winkler · Jens Meier · \\ Bernd Lamprecht · Helmut J. F. Salzer
}

Received: 3 May 2020 / Accepted: 1 September 2020 / Published online: 7 October 2020

(C) Springer-Verlag GmbH Austria, part of Springer Nature 2020

\section{Letter to the editors}

To the editors,

To date (3 May 2020), the coronavirus disease 2019 (COVID-19) pandemic has reached all continents and caused 1,991,562 infections in 213 countries [1]. Preliminary data of Chinese patients infected by the severe acute respiratory syndrome coronavirus 2 (SARS$\mathrm{CoV}-2$ ) indicate an asymptomatic or relatively mild course of disease in younger patients, while older patients with comorbidities are at risk for a severe and fatal course of disease [2]. According to the Chinese Center for Disease Control and Prevention, among 44,672 confirmed COVID-19 cases, only $8.1 \%$ were young adults aged $20-29$ years. The reported case fatality rate was $0.2 \%$ for this age group [3].

C. Schlömmer, MD $(\varangle) \cdot$ M. W. Dünser, MD · J. Meier, MD Department of Anesthesia and Intensive Care Medicine, Kepler University Hospital and Johannes Kepler University, Krankenhausstraße 9, 4020 Linz, Austria

c.schloemmer@gmx.net

M. Antlanger, MD

Department of Internal Medicine 2, Kepler University Hospital and Johannes Kepler University, Linz, Austria

\section{Paar, $\mathrm{PhD}$}

Department of Laboratory Medicine, Kepler University Hospital and Johannes Kepler University, Linz, Austria

\section{Winkler, MD}

Department of Pathology and Microbiology, Kepler

University Hospital and Johannes Kepler University, Linz, Austria

B. Lamprecht, MD · H. J. F. Salzer, MD, MPH

Department of Pulmonology, Kepler University Hospital and

Johannes Kepler University, Linz, Austria
On 13 March 2020 a 27-year-old Caucasian woman with a history of type 1 diabetes mellitus was admitted to the Kepler University Hospital in Linz due to unspecific gastrointestinal symptoms for 4 days. At presentation the oxygen saturation was mildly reduced and the body temperature elevated. The diabetes was not well-controlled with a HbAlc of $13.3 \%$, complicated by long-term sequelae, such as arterial hypertension, chronic kidney disease stage G4, an estimated glomerular filtration rate (eGFR) (CKD-EPI) of $23.8 \mathrm{ml} / \mathrm{min} / 1.73 \mathrm{~m}^{2}$ on admission and obesity (body mass index, BMI $30 \mathrm{~kg} / \mathrm{m}^{2}$ ). During hospital day 1 she developed oxygen desaturation, which required continuous oxygen insufflation via an oxygen mask. Despite the observed hypoxemia, the patient did not complain of dyspnea while exhibiting tachypnea with a normal breathing pattern. The chest X-ray revealed bilateral opacities (Fig. 1, Tables 1 and 2). Since her underlying condition remained unclear and the respiratory situation deteriorated, a nasopharyngeal swab for SARS-CoV-2 (QIAstat-Dx Respiratory 2019nCoV Panel; QIAGEN ${ }^{\circledR}$, Hilden, Germany) was taken confirming COVID-19. On hospital day 2, respiratory function deteriorated within a few hours and the patient had to be admitted to the intensive care unit (ICU) where she required emergency endotracheal intubation due to acute respiratory distress syndrome. Her condition could only be stabilized with invasive mechanical ventilation and prone positioning and 4 days after ICU and 5 days after hospital admission, the patient unexpectedly died due to acute right heart failure.

Recent data indicate an increased risk of a severe course of disease in older patients with COVID-19 and underlying comorbidities, such as arterial hypertension, coronary artery disease, chronic obstructive pulmonary disease, and diabetes mellitus $[2,4,5]$. Of these, diabetes mellitus is associated with a higher 


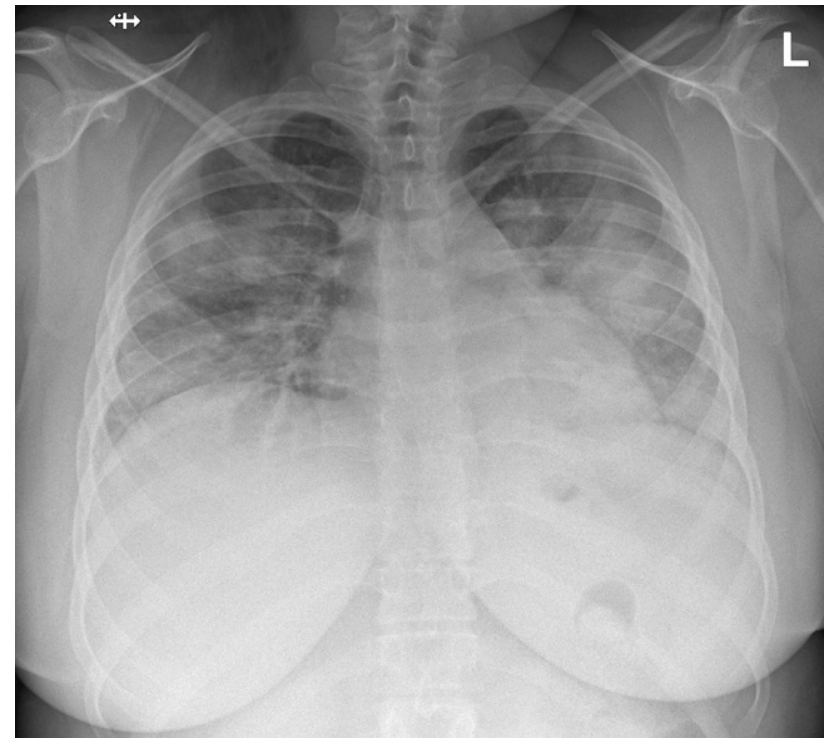

Fig. 1 Chest X-ray, vital signs and laboratory findings of a 27year-old female with COVID-19 at hospital admission. The chest X-ray shows bilateral opacities. Rapid deterioration of respiratory capacities was indicated by an arterial blood gas test at the ward

risk for a fatal outcome $[2,4,6]$. There have been reports that severe and critical courses lead to death in up to $50 \%$ of COVID- 19 cases [2,3]. Nevertheless, the young age and the regenerative capacity of our patient should have helped her fighting the disease.

Another fact worth mentioning is the time of onset of the patient's symptoms, whereby 2 days prior to admission to our hospital, the patient asked for medical treatment at an outpatient department of another hospital. Due to her ongoing gastrointestinal symptoms, she was treated with oral analgesics, proton pump inhibitors and antiemetics, which did not relieve her symptoms. Strikingly, she hardly expressed

Table 1 Vital signs and laboratory findings at hospital admission

\begin{tabular}{|l|l|}
\hline Symptoms & Nausea, vomiting, diarrhea, abdominal pain \\
\hline Oxygen saturation & $93 \%$ \\
\hline Temperature & $37.9^{\circ} \mathrm{C}$ \\
\hline Hemoglobin & $9.2 \mathrm{~g} / \mathrm{dL}$ \\
\hline C-reactive protein & $7.9 \mathrm{mg} / \mathrm{dL}$ \\
\hline Creatinine & $2.65 \mathrm{mg} / \mathrm{dL}$ \\
\hline
\end{tabular}

Table 2 Arterial blood gas test at the ward

\begin{tabular}{|l|l|}
\hline $\mathrm{pH}$ & 7.35 \\
\hline $\mathrm{PaO}_{2}$ & $53.3 \mathrm{~mm} \mathrm{Hg}$ \\
\hline $\mathrm{PaCO}_{2}$ & $41.4 \mathrm{~mm} \mathrm{Hg}$ \\
\hline $\mathrm{S}_{\mathrm{a}} \mathrm{O}_{2}$ & $86 \%$ \\
\hline $\mathrm{P}_{\mathrm{a}} \mathrm{O}_{2}$ partial pressure of oxygen, $\mathrm{P}_{\mathrm{a}} \mathrm{CO}_{2}$ partial pressure of carbon dioxide, \\
$\mathrm{S}_{\mathrm{a}} \mathrm{O}_{2}$ arterial oxygen saturation
\end{tabular}

dyspnea until she was admitted to the ICU. At our hospital, an absent feeling of dyspnea is frequently observed in COVID-19 inpatients, although severe oxygenation problems are present. Preliminary data from China reported gastrointestinal symptoms as uncommon [4, 7]; however, gastrointestinal symptoms (diarrhea, nausea, vomiting, abdominal pain) were observed in 10-20\% of COVID-19 patients as primary characteristics of disease onset [8,9].

Despite our patient's young age, comorbidities severely deteriorated the course of COVID-19 and ultimately lead to a fatal outcome.

Conflict of interest C. Schlömmer, M.W. Dünser, M. Antlanger, C. Paar, M. Winkler, J. Meier, B. Lamprecht, and H.J. F. Salzer declare that they have no competing interests.

\section{References}

1. World Health Organization. Coronavirus disease 2019 (COVID-19) Situation Report - 87.. https://www.who. int/docs/default-source/coronaviruse/situation-reports/ 20200416- sitrep-87- covid-19.pdf?sfvrsn=9523115a_2. Accessed Internet.

2. Zhou F, Yu T, Du R, et al. Clinical course and risk factors for mortality of adult inpatients with COVID-19 in Wuhan, China: a retrospective cohort study. Lancet. 2020; https:// doi.org/10.1016/S0140-6736(20)30566-3.

3. Novel Coronavirus Pneumonia Emergency Response Epidemiology Team. The epidemiological characteristics of an outbreak of 2019 novel coronavirus diseases (COVID19) in China. Zhonghua Liu Xing Bing Xue Za Zhi. 2020;41(2):145-51.

4. Guan W, Ni Z, Hu Y, et al. Clinical characteristics of Coronavirus disease 2019 in China. N Engl J Med. 2020; https://doi.org/10.1056/NEJMoa2002032.

5. Chen N, Zhou M, Dong X, et al. Epidemiological and clinical characteristics of 99 cases of 2019 novel coronavirus pneumonia in Wuhan, China: a descriptive study. Lancet. 2020;395(10223):507-13.

6. Li J, LongX, Luo H, et al. Clinical characteristics of deceased patients infected with SARS-coV-2 in Wuhan, China. SSRN ElectronJ.2020. https://www.ssrn.com/abstract=3546043. Accessed 25 Mar 2020.

7. Huang C, Wang Y, Li X, et al. Clinical features of patients infected with 2019 novel coronavirus in Wuhan, China. Lancet. 2020;395(10223):497-506.

8. Wang $\mathrm{D}, \mathrm{Hu} \mathrm{B}, \mathrm{Hu} \mathrm{C}$, et al. Clinical characteristics of 138 hospitalized patients with 2019 novel Coronavirus-infected pneumonia in Wuhan, China. JAMA. 2020;323(11):1061-1017.

9. Pan L, Mu M, Yang P, et al. Clinical characteristics of COVID-19 patients with digestive symptoms in Hubei, China: a descriptive, cross-sectional, multicenter study. Am J Gastroenterol. 2020; https://doi.org/10.14309/ajg. 0000000000000620.

Publisher's Note Springer Nature remains neutral with regard to jurisdictional claims in published maps and institutional affiliations. 